\title{
Intervalo Hídrico Ótimo utilizado como indicador da qualidade física do solo em perímetro irrigado
}

Thiago Lima da Silva ${ }^{1}$

Antenor de Oliveira Aguiar Netto ${ }^{2}$

Maria Isidória Silva Gonzaga ${ }^{3}$

Edson Patto Pacheco 4

Ariovaldo Antonio Tadeu Lucas ${ }^{5}$

\section{Resumo}

Um dos principais parâmetros para se avaliar as condições físicas do solo é o Intervalo Hídrico Ótimo (IHO), que tem como conceito a incorporação de uma faixa de quantidade de água, as limitações ao desenvolvimento das plantas por aeração, água disponível e resistência do solo à penetração das raízes. 0 objetivo neste trabalho foi avaliar o intervalo hídrico ótimo de um Latossolo Amarelo distrófico com diferentes usos e manejos no perímetro irrigado Piauí, município de Lagarto (SE). Foram selecionados quatro tipos de usos do solo, esses tinham diferentes manejos agrícolas no perímetro irrigado Piauí e profundidades 0 - 0,15 m; 0,15 - 0,30 m e 0,30 - 0,45 m. Os usos distintos consistiram em: a) área sob cultivo de pimenteira malagueta (Capsicum frutensens L.); b) área sob cultivo de maracujazeiro amarelo (Passiflora edulis sims); c) área sob cultivo de maracujazeiro em consórcio com pimenteira malagueta; d) área sob pastagem (Brachiaria decumbens Stapf.). 0 intervalo hídrico ótimo foi determinado por meio da curva de resistência à penetração e da curva de retenção da água no solo e mostrou-se importante indicador para avaliação da qualidade física do solo avaliado sob diferentes usos no perímetro irrigado, em que o manejo empregado afetou sua qualidade física, uma vez que em profundidades maiores todos os usos apresentam restrições ao desenvolvimento do sistema radicular, sendo que a pastagem e o consórcio maracujá e pimenteira apresentam essa restrição já na profundidade superficial $0-0,15 \mathrm{~m}$.

Palavras-chave: Física do solo. Resistência à penetração. Manejo do solo.

\section{Introdução}

O solo desempenha importantes funções tanto nos ecossistemas naturais quanto nos antropizados, incluindo a sustentação e manutenção da qualidade ambiental. Os inúmeros processos e importantes ciclos de transformações que ocorrem no solo e em suas interfaces fazem desse componente uma parte vital para os agroecossistemas. Contudo, o bom desempenho do solo nesses ambientes

\footnotetext{
1 Instituto Federal de Educação, Ciência e Tecnologia de Sergipe, professor pesquisador, Nossa Senhora da Glória, Sergipe, Brasil. thiago.silva@ifs.edu.br. Rodovia Juscelino Kibitsheck, Comunidade Meisinha, Nossa Senhora da Glória, Sergipe, CEP 49680-000.

2 Universidade Federal de Sergipe, professor pesquisador. São Cristóvão, Sergipe, Brasil. antenor.ufs@gmail.com. Av. Marechal Rondon, s/n., Rosa Elze, São Cristóvão, Sergipe, CEP 49100-000.

3 Universidade Federal de Sergipe, professor pesquisador, São Cristóvão, Sergipe, Brasil. mariaisisilva@gmail.com. Av. Marechal Rondon, s/n., Rosa Elze, São Cristóvão, Sergipe, CEP 49100-000.

4 Empresa Brasileira de Pesquisa Agropecuária, pesquisador A, Aracaju, Sergipe, Brasil. edson.patto@embrapa.br. Avenida Beira Mar, 3250, Sementeira, Sergipe, CEP 49025-040.

5 Universidade Federal de Sergipe, professor pesquisador. São Cristóvão, Sergipe, Brasil. aatlucas@gmail.com. Av. Marechal Rondon, s/n., Rosa Elze, São Cristóvão, Sergipe, CEP 49100-000.
} 
depende sobremaneira das condições de seus atributos físicos, químicos e biológicos, os quais podem ser conservados, melhorados ou degradados, de acordo com o uso e com os manejos adotados. Essa compreensão é fundamental para o desenvolvimento de sistemas agrícolas sustentáveis.

Os atributos físicos do solo são fortemente afetados pelas práticas intensivas de cultivo, principalmente para solos naturalmente susceptíveis à degradação em perímetros irrigados, a exemplo dos Latossolos Amarelos encontrados no estado de Sergipe. Esses solos são muito intemperizados e com baixa fertilidade natural, característica que favorece ainda mais os processos de degradação.

Um dos principais parâmetros para se avaliar as condições físicas do solo é chamado de IHO, pois ele insere uma faixa de quantidade de água, limitações ao desenvolvimento das plantas por aeração, água disponível e resistência do solo à penetração das raízes (TORMENA et al., 1998).

De acordo com Fontanela (2008), a principal vantagem da utilização do IHO na avaliação da qualidade física do solo é que ele integra em um único parâmetro os efeitos do potencial mátrico, da porosidade de aeração e da resistência à penetração no crescimento das plantas.

Ainda em seu trabalho, Fontanela (2008) considera o IHO como um parâmetro adequado para avaliação da qualidade física do solo em culturas anuais de solos tropicais. A quantificação do IHO e, posteriormente, a determinação do valor da densidade crítica (Dsc) do solo é de grande importância, pois esse tem grande influência para o crescimento e desenvolvimento das plantas em diferentes manejos de solo.

Segundo Cavalieri et al. (2006), o IHO melhora o conceito de água disponível entre capacidade de campo (cc) e ponto de murcha permanente (pmp), pois considera as limitações da aeração e resistência à penetração. Nos solos em que os sistemas de manejo ajudam na melhoria da sua qualidade estrutural, o IHO é igual à água disponível (ad). Já em situações de degradação estrutural, o IHO tem seu limite superior e inferior estabelecido pela umidade referente à porosidade de aeração ( $\theta p a)$ e resistência do solo à penetração ( $\theta r p)$, respectivamente, sendo a pior situação possível.

O perímetro irrigado Piauí foi inaugurado em 1987 sem intervenção fundiária, é constituído em sua maioria por pequenos lotes com menos de 5 hectares onde as principais culturas produzidas são: Batata Doce, Inhame, Mandioca, Repolho, Pimenta Malagueta e Jalapeño, Pimentão, Quiabo, Tomate, Maracujá, Amendoim, Mamão, Laranja e Mudas Citrícolas. A área do projeto está totalmente contida na bacia do Rio Piauí (SEPLANTEC, 2002).

Nesse contexto, o presente trabalho tem por objetivo avaliar o Intervalo Hídrico Ótimo de um Latossolo Amarelo Distrófico com diferentes usos e manejos no perímetro irrigado Piauí, município de Lagarto (SE).

\section{Material e métodos}

O estudo foi realizado no município de Lagarto, localizado no centro-sul do estado de Sergipe. Segundo a classificação climática de Köppen, o clima da área do perímetro é do tipo As, com precipitação média de 1.020,6 $\mathrm{mm} \mathrm{ano}^{-1} \mathrm{e}$ as temperaturas médias do ar dos meses mais frios ocorrem em julho e agosto, com valores em torno de $22,5^{\circ} \mathrm{C}$, e o mês mais quente é janeiro, com média de $26,2^{\circ} \mathrm{C}$. As temperaturas médias mínimas mensais estão compreendidas entre 18 e 22 ${ }^{\circ} \mathrm{C}$ e as temperaturas médias máximas mensais estão entre 26 e $32{ }^{\circ} \mathrm{C}$ (SOUSA et. al., 2010). 0 relevo é de superfície pediplanada e dissecada, com aprofundamento de drenagem muito fraca à mediana. Os solos são Planossolos, Litossolos eutróficos, Argissolos Vermelho Amarelo e Latossolos Amarelos, cobertos por uma vegetação de Campos Limpos, Campos Sujos, Capoeira e Caatinga (SEPLANTEC, 2002). 
Foram selecionados quatro diferentes tipos de uso do solo, sendo cinco lotes de cada manejo e três profundidades: P1 0-0,15 m; P2 0,15-0,30 m e P3 0,30-0,45 m. Os usos do solo consistiram em: A1 - área sob cultivo de pimenteira malagueta (Capsicum frutensens L.); A2 - área sob cultivo de maracujazeiro amarelo (Passiflora edulis sims); A3 - área sob cultivo de maracujazeiro em consórcio com pimenteira malagueta; A4 - área sob pastagem (Brachiaria decumbens Stapf.). O solo das áreas avaliadas foi classificado como Latossolo Amarelo Distrófico (EMBRAPA, 2006).

Amostras de solo indeformadas foram coletadas em cilindros (anéis) volumétricos, nas diferentes profundidades e levadas ao laboratório de física do solo da Embrapa Tabuleiros Costeiros. Para determinação da umidade do solo na capacidade de campo ( $\theta c c)$ foi considerada a aplicação da tensão em 10 kPa e para umidade do solo obtida no ponto de murcha permanente ( $\theta$ pmp), a tensão em $1500 \mathrm{kPa}$. A disponibilidade total de água no solo ( $\theta \mathrm{ad})$ foi calculada pela diferença entre $\theta c c$ e Өpmp, a densidade do solo (Ds) foi determinada pela relação entre a massa do solo seco a $105^{\circ} \mathrm{C}$ e o volume do anel (EMBRAPA,1997).

Para o cálculo da porosidade de aeração de $10 \%$ foi determinado o volume total de poros (VTP $\mathrm{m}^{3} \cdot \mathrm{m}^{-3}$ ) pelo método de percentagem de saturação em volume conforme Embrapa (2007), e utiliza-

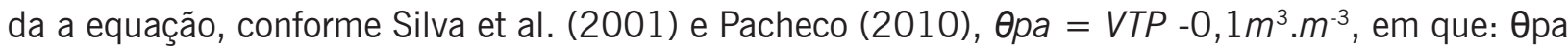
$=$ Porosidade de aeração a $10 \%$; VTP $=$ Volume total de poros $\left(\mathrm{m}^{3} \cdot \mathrm{m}^{-3}\right)$.

Foram utilizadas a mesa de tensão e o extrator de Richards para determinação das umidades retidas em oito tensões matriciais $(1,4,6,10,33,100,500$ e $1500 \mathrm{kPa})$. Essas amostras foram submetidas ao ensaio de resistência à penetração em laboratório (RPL), utilizando um penetrógrafo de bancada da marca Marconi, equipado com célula de carga contendo haste com cone de $4 \mathrm{~mm}$ de diâmetro e ângulo de $45^{\circ}$. A velocidade de penetração constante foi calibrada para $10 \mathrm{~mm} \mathrm{~min}^{-1}$, tendo cada ensaio uma duração de 144 segundos. Para o cálculo de resistência à penetração média de cada ensaio, foram considerados apenas os registros de força de penetração entre 60 e 120 segundos, eliminando os dados de resistência nas extremidades das amostras, sendo que o equipamento registra um dado de força de penetração (kgf) a cada segundo. A resistência à penetração foi calculada conforme equação apresentada a seguir (PACHECO, 2010):

$R P L=\left(\frac{F p}{0,1275}\right) \times 98,0665$, em que:

$\mathrm{RPL}=$ resistência à penetração em laboratório $(\mathrm{kPa}) ; \mathrm{Fp}=$ força de penetração média (kgf);

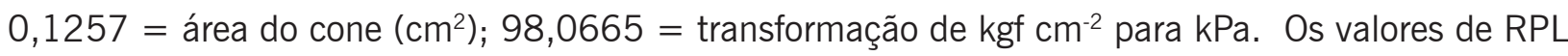
foram ajustados a modelos não lineares, em função do conteúdo volumétrico de água $(\theta)$, utilizando-se a descrita por Dias Junior (1994), $R P=10^{(a+b \theta)}$ sendo RP a resistência à penetração $(\mathrm{kPa})$; $a$ e $b$ os parâmetros de ajuste da equação e $\theta$ o conteúdo volumétrico de água $\left(\mathrm{cm}^{3} \mathrm{~cm}^{-3}\right)$.

Para determinação da umidade volumétrica do solo, quando a resistência atinge $2000 \mathrm{kPa}$ (Өrp), foi considerado a seguinte equação:

$\theta r p=\left[\ln \left(\frac{2000}{a}\right)\right] / b$, em que:

In = Logarítmo neperiano; 2.000 = Valor da resistência do solo considerado como limite para o desenvolvimento do sistema radicular; a e b os parâmetros de ajuste da equação (FARIAS, 2013).

O Intervalo Hídrico Ótimo foi determinado conforme metodologia descrita por Wu et al. (2003), por meio da curva de resistência à penetração e da curva de retenção da água no solo. A determinação do IHO segue as seguintes condições: (a) Se $(\theta p a \geq \theta c c)$ e $(\theta r p \leq \theta p m p)=>I H O=\theta c c-$ 
$\theta p m p ;(b) \operatorname{Se}(\theta p a \geq \theta c c)$ e $(\theta r p \geq \theta p m p)=>I H O=\theta c c-\theta r p ;(c)$ Se $(\theta p a \leq \theta c c)$ e $(\theta r p \leq \theta p m p)$ $=>\mathrm{IHO}=\theta p a-\theta p m p ;(d) \operatorname{Se}(\theta p a \leq \theta c c)$ e $(\theta r p \geq \theta p m p)=>I H O=\theta p a-\theta r p$.

Em que: IHO = Intervalo Hídrico Ótimo; $\theta p a=$ umidade volumétrica do solo em que a porosidade de aeração é $\leq 0,1 \mathrm{~m}^{3} \cdot \mathrm{m}^{-3} ; \theta c c=$ umidade volumétrica na capacidade de campo (água retida na tensão $10 \mathrm{kPa}$ ); $\theta \mathrm{pmp}=$ umidade volumétrica no ponto de murcha permanente (água retida na tensão de $1.500 \mathrm{kPa}$ ); $\theta r p=$ umidade volumétrica quando a resistência do solo à penetração é igual a $2.000 \mathrm{kPa}$.

\section{Resultados e discussão}

Os resultados do intervalo hídrico ótimo estão apresentados na Tabela 1.

Tabela 1. Porosidade de aeração ( $\theta p a)$, capacidade de campo $(\theta c c)$, ponto de murcha permanente $(\theta p m p)$, Água Disponível ( $\theta a d)$, resistência à penetração em laboratório (Өrp), intervalo hídrico ótimo (IHO) e densidade do solo (Ds), em diferentes profundidades em um Latossolo Amarelo sob diferentes usos no Perímetro Irrigado Piauí, município de Lagarto (SE).

\begin{tabular}{|c|c|c|c|c|c|c|c|c|}
\hline USO DO SOLO & $\begin{array}{l}\theta p a \\
\left(m^{3} \cdot m^{-3}\right)\end{array}$ & $\begin{array}{l}\theta c c \\
\left(m^{3} \cdot m^{-3}\right)\end{array}$ & $\begin{array}{l}\theta p m p \\
\left(m^{3} \cdot m^{-3}\right)\end{array}$ & $\begin{array}{l}\text { Oad } \\
\left(\mathrm{m}^{3} \cdot \mathrm{m}^{-3}\right)\end{array}$ & $\begin{array}{l}\text { Orp } \\
\left(m^{3} \cdot m^{-3}\right)\end{array}$ & $\begin{array}{l}\text { IHO } \\
\left(m^{3} \cdot m^{-3}\right)\end{array}$ & $\begin{array}{l}\text { Ds } \\
\left(\mathrm{kg} \cdot \mathrm{dm}^{-3}\right)\end{array}$ & $\mathbf{R}^{2}$ \\
\hline \multicolumn{9}{|c|}{ Profundidade de $0-0,15 \mathrm{~m}$} \\
\hline Maracujazeiro & 0,306 & 0,200 & 0,025 & 0,175 & 0,018 & 0,175 & 1,47 & 0,85 \\
\hline Pastagem & 0,305 & 0,257 & 0,055 & 0,202 & 0,058 & 0,199 & 1,54 & 0,57 \\
\hline Pimenteira & 0,362 & 0,187 & 0,046 & 0,141 & 0,045 & 0,141 & 1,50 & 0,58 \\
\hline Consórcio & 0,296 & 0,192 & 0,050 & 0,142 & 0,104 & 0,088 & 1,47 & 0,78 \\
\hline \multicolumn{9}{|c|}{ Profundidade de $0,15-0,30 \mathrm{~m}$} \\
\hline Maracujazeiro & 0,219 & 0,203 & 0,023 & 0,180 & 0,079 & 0,124 & 1,57 & 0,81 \\
\hline Pastagem & 0,272 & 0,227 & 0,018 & 0,209 & 0,080 & 0,147 & 1,57 & 0,83 \\
\hline Pimenteira & 0,252 & 0,169 & 0,027 & 0,142 & 0,085 & 0,084 & 1,55 & 0,89 \\
\hline Consórcio & 0,279 & 0,199 & 0,071 & 0,128 & 0,117 & 0,082 & 1,55 & 0,74 \\
\hline \multicolumn{9}{|c|}{ Profundidade de 0,30 - 0,45 m } \\
\hline Maracujazeiro & 0,232 & 0,188 & 0,029 & 0,159 & 0,087 & 0,101 & 1,59 & 0,82 \\
\hline Pastagem & 0,286 & 0,229 & 0,021 & 0,208 & 0,089 & 0,140 & 1,59 & 0,92 \\
\hline Pimenteira & 0,360 & 0,157 & 0,038 & 0,119 & 0,049 & 0,108 & 1,58 & 0,96 \\
\hline Consórcio & 0,317 & 0,216 & 0,070 & 0,146 & 0,110 & 0,106 & 1,58 & 0,94 \\
\hline
\end{tabular}

Fonte: Silva, T. L.

Observa-se na profundidade de 0 - 0,15m que o uso do solo com pastagem apresentou maiores volumes de água retidos entre usos estudados. Umidades na capacidade de campo e no ponto de murcha permanente, além de maior Intervalo Hídrico Ótimo e água disponível, confirmam a contribuição dessa cultura na estruturação física do solo. Porém, o IHO de 0,199 $\mathrm{m}^{3} \cdot \mathrm{m}^{-3}$ nessa cultura encontra-se com volumes abaixo da água disponível, o que pode indicar restrições ao desenvolvimento radicular devido à resistência do solo à penetração acima dos limites de bom desenvolvimento.

Pacheco (2010) encontrou em seu trabalho o Intervalo Hídrico Ótimo menor que os deste estudo, porém maior em áreas plantadas com cana-de-açúcar, variando entre 0,056 e 0,066 $\mathrm{m}^{3} . \mathrm{m}^{-3}$ em comparação com uma mata nativa que apresentou $0,031 \mathrm{~m}^{3} \cdot \mathrm{m}^{-3}$. Segundo esse autor, o cultivo dessa espécie favoreceu maior disponibilidade de água no horizonte estudado. 
O uso do solo com a cultura do maracujazeiro e da pimenteira apresentam valores de água disponível e IHO 0,175 e 0,175 $\mathrm{m}^{3} \cdot \mathrm{m}^{-3}$ e 0,141 e 0,141 $\mathrm{m}^{3} \cdot \mathrm{m}^{-3}$, respectivamente, menores que o da pastagem, porém esses usos mostram-se em condições físicas ideais nessa profundidade, pois a água disponível é igual ao IHO.

Em condições de degradação estrutural, ocorre a redução na porosidade total, o que não ocorre nesses usos que apresentaram maiores valores de porosidade de aeração ( $\theta p a), 0,306$ e 0,362 $\mathrm{m}^{3} \cdot \mathrm{m}^{-3}$, respectivamente (CAVALIERI et al., 2006).

Apesar de o uso da pastagem na profundidade de 0 - 0,15 m apresentar maior Intervalo Hídrico Ótimo, observa-se que a umidade da resistência à penetração em laboratório é maior que o ponto de murcha permanente, neste caso o Intervalo Hídrico Ótimo foi menor que a água disponível, isso também ocorre no uso do consórcio. Segundo Pacheco (2010), nas áreas, mesmo havendo umidade acima do ponto de murcha permanente para desenvolvimento de raízes, a resistência à penetração torna-se restritiva ao crescimento radicular, portanto, o IHO é menor do que a água disponível, ou seja, é o volume de água contido entre a $\operatorname{rrp~e~} \theta c c$. Nos usos da pimenteira e do maracujazeiro, o Intervalo Hídrico Ótimo foi igual à água disponível, que é o ideal para um bom desenvolvimento do sistema radicular por não apresentar restrições ao desenvolvimento do sistema radicular. A contribuição do sistema radicular fasciculado das poáceas na estruturação do solo, seja pela adição de matéria orgânica, seja pelo crescimento, pode ter influenciado um maior Intervalo Hídrico Ótimo, principalmente nas primeiras profundidades avaliadas.

O uso da pastagem apresentou maiores médias de densidade do solo em comparação com os outros usos. Segundo Trimble e Mendel (1995), essa característica de compactação em pastos ocorre devido à força aplicada ao solo pelos cascos dos animais que durante o pastejo transfere a massa do corpo apenas para as patas, sendo essas de pequena área, o que aumenta pressão pontual contribuindo para essa compactação e pode estar ocorrendo no uso da pastagem no perímetro irrigado estudado.

O armazenamento de água no solo depende do tamanho e quantidade de poros, principalmente dos microporos. Segundo Libardi (2000), quanto menor o tamanho dos poros mais intenso será o fenômeno de capilaridade e, portanto, maior será a retenção de água no solo.

Nas outras profundidades avaliadas 0,15-0,30m e 0,30-0,45m, os usos apresentam médias dos Intervalos Hídricos Ótimos menores que na profundidade de 0-0,15 m, porém observa-se que em profundidade todos os usos apresentam o IHO menor que a água disponível, ou seja, a resistência à penetração torna-se restritiva ao crescimento radicular. Segundo Cavalieri et al. (2006), nos solos em que os sistemas de manejo propiciam melhoria da sua qualidade estrutural, o IHO é numericamente igual à água disponível. Por outro lado, em situações de degradação estrutural, existe uma diminuição da porosidade total influenciada pela alteração na distribuição do tamanho dos poros.

A Figura 1 mostra as curvas de resistência à penetração em função da umidade do solo na profundidade de 0-0,15m. Observa-se que o uso do consórcio apresentou maior resistência à penetração quando a umidade do solo está no ponto de murcha permanente, ou seja, quando a umidade aproxima-se do ponto de murcha, a resistência à penetração oferece restrições físicas ao desenvolvimento da cultura. Os usos da pastagem e do consórcio apresentaram, nesta umidade, resistência acima de $2.000 \mathrm{kPa}$. 


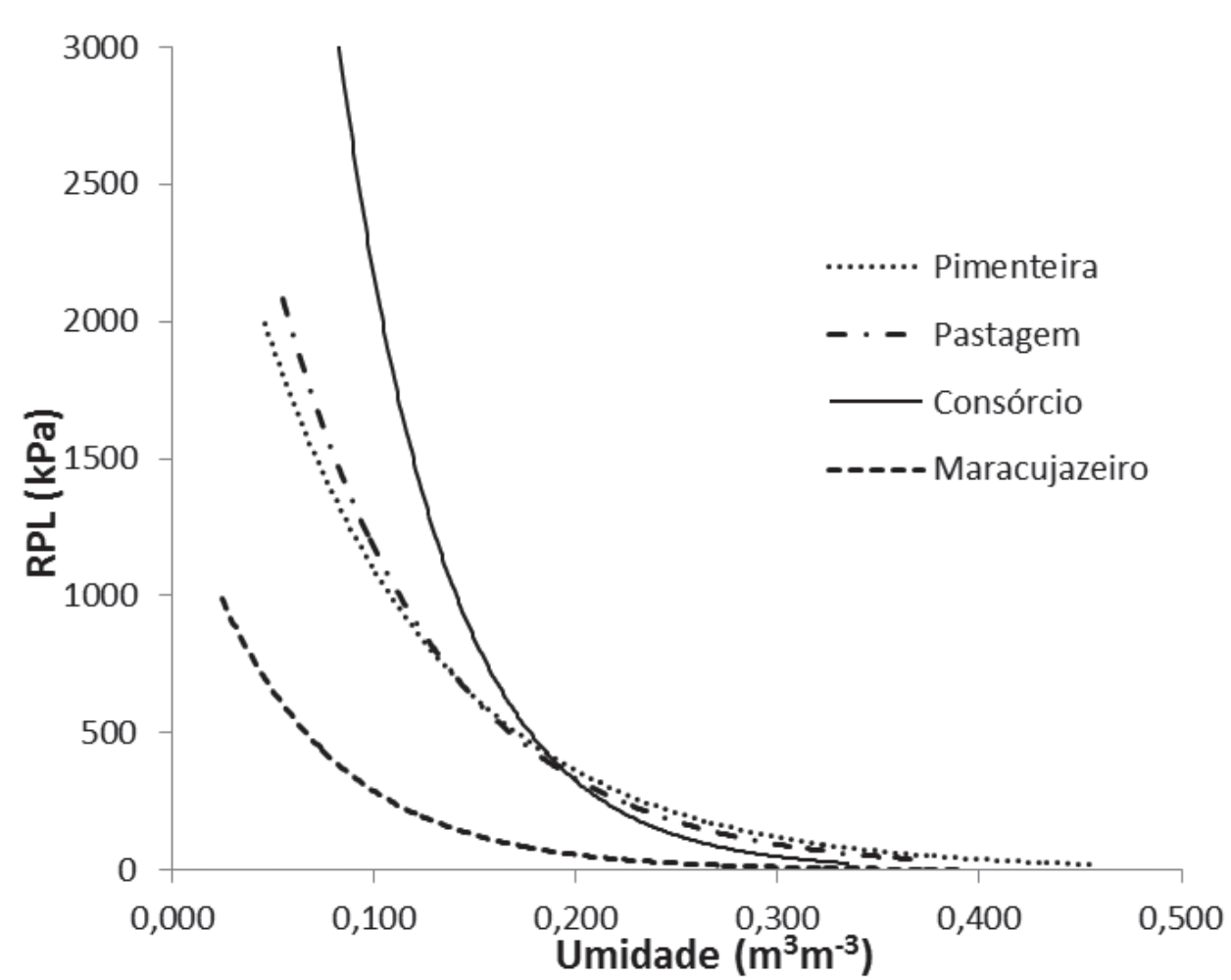

Figura 1. Curvas de resistência à penetração na profundidade $0-0,15 \mathrm{~m}$ em função da umidade do solo, para quatro usos em um Latossolo Amarelo distrófico, no perímetro irrigado Piauí, município de Lagarto (SE). Fonte: SILVA, T. L.

0 valor de resistência à penetração igual a $2.000 \mathrm{kPa}$ tem sido amplamente utilizado como crítico para o desenvolvimento das plantas, segundo Richart et al. (2005) e Reichert et al. (2007), e principalmente para definir um limite inferior de água no solo na quantificação do Intervalo Hídrico Ótimo (SILVA et al., 1994). Nessa profundidade os usos da pimenteira e do maracujazeiro não apresentaram umidade de resistência à penetração maior que a umidade de ponto de murcha, isso propicia um desenvolvimento sem restrições ao desenvolvimento radicular das culturas. Quando isso ocorre, a faixa ideal de umidade é a água disponível, ou seja, os limites ideais estão entre a capacidade de campo e o ponto de murcha permanente.

A Figura 2 apresenta as curvas de resistência à penetração dos usos na profundidade de 0,15$0,30 \mathrm{~m}$ em função da umidade do solo. Observa-se que, em todos os usos, a resistência à penetração ultrapassa $2.000 \mathrm{kPa}$, ou seja, no intervalo da água disponível existem restrições para o desenvolvimento do sistema radicular, e o Intervalo Hídrico Ótimo é menor que a disponibilidade de água, sendo que na menor umidade do solo, o uso que apresenta menor resistência, que neste trabalho foi o da pastagem, apresenta duas vezes mais resistência que o limite crítico considerado de $2.000 \mathrm{kPa}$. 


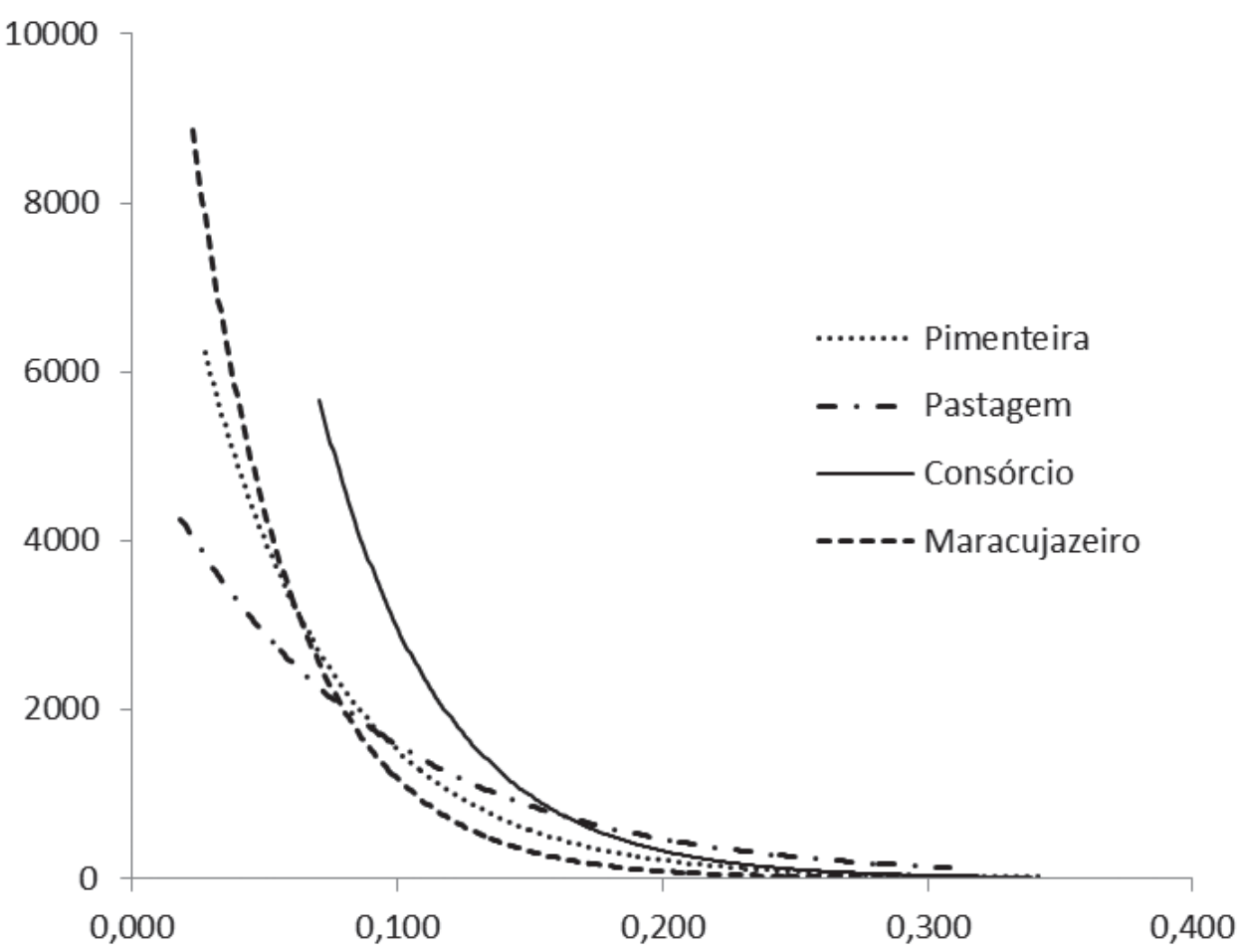

Umidade $\left(\mathrm{m}^{3} \mathrm{~m}^{-3}\right)$

Figura 2. Curvas de resistência à penetração na profundidade 0,15-0,30 m em função da umidade do solo, para quatro usos em um Latossolo Amarelo Distrófico, no perímetro irrigado Piauí, município de Lagarto (SE). Fonte: SILVA, T. L.

Aguiar Netto et al. (2006), estudando o processo de salino-sodificação no perímetro irrigado Jabiberi (SE), observaram que camadas mais profundas de solo foram afetadas fisicamente por manejos empregados em camadas superficiais. A presença de sais como o sódio trocável pode propiciar a dispersão do solo por meio do processo de lixiviação do material desagregado e formar uma camada mais densa nas maiores profundidades, o que pode oferecer uma maior resistência em determinada umidade do solo.

A Figura 3 apresenta os resultados das curvas de resistência à penetração dos usos na profundidade de 0,30-0,45 m. Observa-se que todos os usos apresentaram resistência acima de 2.000 $\mathrm{kPa}$. O uso do solo com a cultura do maracujazeiro foi o que apresentou maior resistência e menor IHO. Nesse tipo de situação, mesmo existindo água no solo próximo a umidade de ponto de murcha permanente, o solo já apresenta restrições ao desenvolvimento da raiz, isso indica que, mesmo apresentando densidades baixas, a resistência dele à penetração restringe o crescimento radicular afetando todo o desenvolvimento da planta (KAISER et al., 2009). 


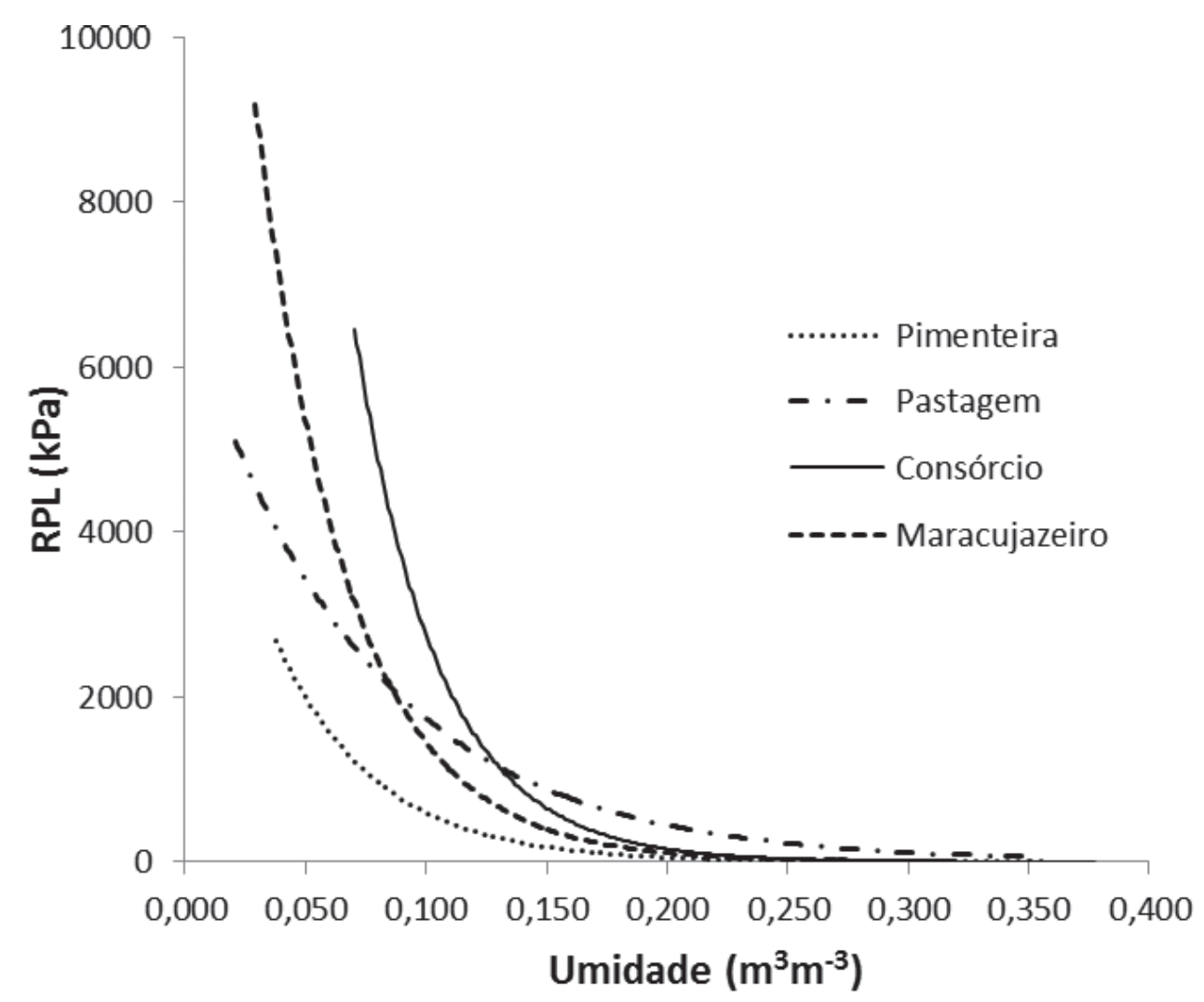

Figura 3. Curvas de resistência à penetração na profundidade 0,30 - 0,45 m em função da umidade do solo, para quatro usos em um Latossolo Amarelo distrófico, no perímetro irrigado Piauí, município de Lagarto (SE). Fonte: SILVA, T. L.

É fundamental para o crescimento da planta que o solo apresente condições favoráveis ao crescimento das raízes, o que permite explorar um maior volume de solo em profundidade, aumentando o acesso à água e reduzindo os riscos de deficiência hídrica (KAISER et al., 2009).

Ainda segundo os autores, uma das principais causas físicas do solo para a falta de desenvolvimento do sistema radicular é a resistência à penetração (STRECK, 2003; COLLARES et al., 2006). $\mathrm{O}$ efeito da resistência à penetração, principalmente em profundidade, depende da umidade do solo.

No solo com a cultura do maracujazeiro e do consórcio, o preparo inicial foi conduzido em maior profundidade que nos outros usos devido às condições de seu sistema radicular, isso pode ter influenciado os resultados de resistência e IHO. Segundo Bengough et al. (2006), a movimentação do solo altera as condições físicas como a densidade e porosidade causando restrições ao desenvolvimento do sistema radicular, isso pode ser percebido já em poucas variações do conteúdo de água no solo.

A presença de água no solo é imprescindível para o processo de crescimento do sistema radicular pois a capacidade de a planta vencer a resistência do solo, além da umidade, depende da espessura da raiz e de susbstâncias mucilaginosas liberadas por elas, que agem como lubrificantes, facilitando seu desenvolvimento (BENGOUGH et al., 2006). Em todos os usos na profundidade de 0,15-0,30m e 0,30-0,45m, as umidades próximas a umidade no ponto murcha permanente, apresentando resistência acima de $2.000 \mathrm{kPa}$, ou seja, acima dos limites críticos de desenvolvimento das plantas. Pode-se inferir que a falta de manejo adequado durante o preparo do solo pode ser responsável por causar o aumento da resistência principalmente em profundidade nesses solos, isso pode levar à utilização de escarificadores e subsoladores nos lotes, para que as culturas tenham um desenvolvimento das raízes (PACHECO, 2010). 


\title{
Conclusão
}

Em camadas subsuperficiais, o IHO é afetado pelo manejo empregado nas culturas do maracujazeiro, pastagem, pimenteira e o consórcio (maracujazeiro e pimenteira) de um Latossolo Amarelo Distrófico no perímetro irrigado Piauí (SE).

\section{Least limiting water range used as an indicator of soil physical quality at irrigated perimeter}

\begin{abstract}
One of the main parameters to evaluate the physical conditions of soil is the Least Limiting Water Range (LLWR), which has as concept the incorporation of a range of water quantity, the limitations to plant growth by aeration, available water and soil resistance to root penetration. Thus, the objective of this study was to evaluate the LLWR of a Yellow Dystrophic Latosol with different uses and management in the irrigated perimeter of Piauí, in Lagarto city, Sergipe State. It was selected four distinct types of land uses with different agricultural management in the irrigated perimeter of Piauí and three depths: from 0.0 to $0.15,0.15$ to 0.30 and 0.30 to $0.45 \mathrm{~m}$. The different uses were: a) area cropped with chilli pepper (Capsicum frutensens L.); b) area with passion fruit tillage (Passiflora edulis Sims); c) area with passion fruit tillage consorted with chili pepper; d) area under pasture (Brachiaria decumbens Stapf.). The LLWR range was determined by the soil curves of penetration resistance and water retention. LLWR showed an important indicator to evaluate the physical quality of soils under different land uses evaluated in the irrigated perimeter of Piauí, where the management practices used affected the soil physical quality. Since at greater depths all uses have restrictions on root development, the pasture and the passion fruit consortium and pepper have limitation in shallow depth of 0.0 to $0.15 \mathrm{~m}$.
\end{abstract}

Keywords: Soil physics. Penetration resistance. Soil management.

\section{Referências}

AGUIAR NETTO, A. O.; MACHADO, R.; BARRETO, M. C. V. Diagnóstico do processo de salino-sodificação no perímetro irrigado jabiberí-SE. Revista Irriga, Botucatu (SP), v. 11, n. 4, p. 448-459, 2006.

BENGHOUGH, A. G.; BRANSBY, M. F.; HANS, J.; McKENNA, S. J.; ROBERTS, T. J. EVALENTINE, T. A. Root responses to soil physical conditions: Growth dynamics from field to cell. Journal of Experimental Botany, v. 57, p. 437-447, 2006.

CAVAlieRI, K. M. V.; TORMENA, C. A.; VIDIGAL FILHO, P. S.; GONÇAlVES, A. C. A.; COSTA, A. C. da. Efeito de sistemas de preparo nas propriedades físicas de um Latossolo Vermelho distroférrico. Revista Brasileira de Ciência do Solo, v. 30, p. 137-147, 2006.

COLLARES, G. L.; REINERT, D. J.; REICHERT, J. M.; KAISER, D. R. Qualidade física do solo na produtividade da cultura do feijoeiro num Argissolo. Pesquisa Agropecuária Brasileira, v. 41, p. 1663-1674, 2006. 
DIAS JUNIOR, M. S. Compression of three soils under longterm tillage and wheel traffic. 1994, 114p. Doutorado em Crop and Soil Sciences. Michigan State University, East Lansing, Michigan, 1994.

EMPRESA BRASILEIRA DE PESQUISA AGROPECUÁRIA -EMBRAPA. Centro Nacional de Pesquisa de Solos. Manual de métodos e análise de solo. Rio de Janeiro, 1997.

EMPRESA BRASILEIRA DE PESQUISA AGROPECUÁRIA - EMBRAPA. Centro Nacional de Pesquisa de Solos. Sistema brasileiro de classificação de solos. 2. ed. Rio de Janeiro, 2006.

FARIAS, I. L. de; PACHECO, E. P.; VIÉGAS, P. R. A. Characterisation of the optimal hydric interval for a yellow argisol cultivated with sugarcane on the coastal plains of Alagoas, Brazil. Revista Ciência Agronômica, v. 44, n. 4, p. 669-675, out./dez. 2013.

FONTANELA, E. Parâmetros físico-hídricos de um Latossolo sob diferentes sistemas de manejo e níveis de tráfego. 2008. 78p. Dissertação (Programa de Pós-Graduação em Ciência do Solo). Universidade Federal de Santa Maria, Santa Maria, 2008

KAISER, D. R.; REINERT, D. J.; REICHERT, J. M.; COLLARES, G. L.; KUNZ, M. Intervalo hídrico ótimo no perfil explorado pelas raizes de feijoeiro em um latossolo sob diferentes níveis de compactação.

Revista Brasileira de Ciencias do Solo, v. 33, p. 845-855, 2009.

LIBARDI, P. L. Dinâmica da água no solo. 2. ed. Piracicaba, p. 509, 2000.

PACHECO, E. P.; Estudo da compressibilidade e qualidade de um argissolo amarelo cultivado com cana-de-açúcar nos tabuleiros costeiros de Alagoas. 2010. 118p. Tese (Programa de Pós-graduação em Ciência do Solo). Universidade Federal Rural de Pernambuco, Pernambuco, 2010.

REICHERT, J. M.; SUZUKI, L, E. A. S.; REINERT, D. J. Compactação do solo em sistemas agropecuários e florestais: identificação, efeitos, limites críticos e mitigação. In: CERETTA, C. A.; SILVA, L. S.; REICHERT, J. M. Tópicos em Ciência do Solo. Viçosa: SBCS, v. 5, p. 49-134, 2007.

RICHART, A., FILHO, J. T., BRITO, O. R., LLANILLO, R. F., FERREIRA, R. Compactação do solo: causas e efeitos. Semina: Ciências Agrárias, Londrina, v. 26, n. 3, p. 321-344, 2005.

SECRETARIA DE ESTADO DO PLANEJAMENTO E DA CIÊNCIA E TECNOLOGIA - SEPLANTEC. Projeto Cadastro da Infra-Estrutura Hídrica do Nordeste - Sergipe, Aracaju, mai., 2002. Disponível em: <http://www.cprm.gov.br/arquivos/pdf/dehid/Sergipe/Lagarto.pdf>. Acesso em: 15 mar. 2012.

SILVA, A. P.; KAY, B. D.; PERFECT, E. Characterization of the least limiting water range of soils. Soil Science Socety of America Journal, v. 58, p. 1775-1781, 1994.

SILVA, A. P.; NADLER, A.; KAY, B. D. Factors contributing to temporal stability in spatial patterns of water content in the tillage zone. Soil and Tillage Research, v. 58, p. 207-218, 2001.

SOUSA, I. F. de; SILVA, V. P. R.; SABINO, F. G.; AGUIAR NETTO, A. O.; SILVA, B. K. N.; AZEVEDO, P. V. de. Evapotranspiração de referência nos perímetros irrigados do estado de Sergipe. Revista Brasileira de Engenharia Agrícola e Ambiental, v. 14, n. 6, p. 633-644, 2010. 
STRECK, C. A. Compactação do solo e seus efeitos no desenvolvimento radicular e produtividade da cultura do feijoeiro e da soja. 2003. 83p. Dissertação (Programa de Pós-Graduação em Agronomia). Universidade Federal de Santa Maria, Santa Maria, 2003.

TORMENA, C. A.; SILVA, A. P. da; LIBARDI, P. L. Caracterização do intervalo hídrico ótimo de um Latossolo Roxo sob plantio direto. Revista Brasileira de Ciência do Solo, Viçosa, v. 22, n. 4, p. 573 581, 1998.

TRIMBLE, S.W.; MENDEL, A. C. The cow as a geomorphic agent - A critical review. Geomorphology, v. 13, p. 233-253, 1995.

WU, L.; FENG. G.; LETEY, J.; FERGUSON, L.; MITCHELL, J.; McCULLOUGH-SANDEN, B.; MARKEGARD. G. Soil management effects on the nonlimiting water range. Geoderma, v. 114, p. 401-414, 2003.

\section{Histórico editorial}

Submetido em: 18/10/2015

Aceito em: 06/01/2016 